\title{
Percutaneous transluminal coronary angioplasty: catheter technology and procedural guidelines
}

\author{
Adam D Timmis
}

In the April issue of the British Heart Journal de Feyter et al from the Thoraxcenter described their angioplasty experience with the monorail technique in 1000 patients. ${ }^{1}$ The results were excellent with success in $92 \%$ of cases and major complications in only $3.3 \%$. They concluded that the monorail technique is safe and effective but, in the absence of a randomised trial, were careful to avoid firm statements about how it compares with other techniques. A randomised trial would be a formidable and perhaps impossible undertaking for the reasons discussed in de Feyter et al's paper. Without this information to guide the selection of angioplasty equipment, most operators pragmatically use a limited selection of familiar catheters, experimenting with something new only if it seems to offer special advantages.

New technology should be judged by its ability to improve the results of angioplasty by solving specific procedural problems. Early reports identified inability to cross the coronary stenosis as the commonest cause of failed angioplasty and this prompted the introduction of the steerable guide wire, which substantially improved matters by increasing rates of passage from 78 to $92 \%$ in the National Heart, Lung, and Blood Institute Registry report. ${ }^{2}$ There remained, however, a considerable number of cases in which, though the stenosis was crossed with the guide wire, it proved impossible to pass the stenosis with the tip of the balloon catheter either because the stenosis was too tight or because it was located distally in the coronary vessel. Manufacturers responded by developing guide wires and catheters with ever more favourable mechanical characteristics ${ }^{3}$ so that this too has become an unusual cause of failure. Attention is now being directed towards treatment of the chronically occluded vessel and success rates are already improving though there is less optimism about finding purely technological solutions to the problems of coronary reocclusion and restenosisdevelopments in pharmacology are expected to be as important as technology.

This article summarises currently available angioplasty technology and attempts to provide guidelines for selection of catheters and guide wires.

Hospital, London

A D Timmis

Correspondence to:

Dr Adam D Timmis,

London Chest Hospital,

Bonner Road,
London E2 9JX

Accepted for publication

21 February 1990

\section{Angioplasty technology}

GUIDING CATHETER

Guiding catheters have an outer polyurethane (or polyethylene) layer providing stiffness and memory, an underlying wire matrix for transmission of torque, and a luminal lining of Teflon. They are larger than conventional diagnostic catheters with a relatively short non-tapered tip to accommodate the dilatation system; they are also stiffer to provide back up and support. These features all increase the risk of damage to the intima at the coronary ostium, particularly during deep superselective engagement. The risk is only partially offset by provision of a soft catheter tip, and considerable care is necessary if these catheters are to be used safely.

The catheter is required to provide a stable platform for the advancement of the dilatation balloon. The lumen must be large enough not only to accommodate the dilatation system but also to deliver contrast and for pressure monitoring. 9F catheters may be required for complex angioplasty with simultaneous introduction of twin dilatation catheters but for most cases large lumen (up to 0.079 inch) $8 \mathrm{~F}$ catheters are preferred because they engage more comfortably with less risk of intimal damage or complications at the arterial puncture site. Side hole catheters are available to preserve perfusion pressure in the event of coronary wedging, but because they allow contrast spillage into the coronary sinuses visualisation is less satisfactory.

\section{DILATATION CATHETER}

Essential components of the dilatation catheter are the shaft with at least one central lumen for inflation of the distally located balloon. The guide wire may be fixed at the tip of the catheter ("fixed wire" system) but more commonly "over the wire" systems are used, requiring a second lumen for the guide wire running the length of the catheter. In the monorail catheter, however, the second lumen is confined to a short $(17-25 \mathrm{~cm})$ track at the distal end and the guide wire provides a "sliding rail" along which the catheter can be passed.

\section{Balloon technology}

Various balloon polymers are used including polyvinyl chloride (USCI), polyethylene (ACS, Medtronic), polyolefin copolymer (SciMed), and polyethylene terephthalate (USCI). The distensibility, pressure capability, profile, and friction characteristics of these materials are different. Distensibility depends on the compliance (pressure/volume relation) of the polymer, and polyethylene 
terephthalate (unlike the other commonly used balloon materials) is non-compliant, maintaining a relatively constant balloon size over a range of inflation pressures. The greater compliance of the other balloons causes them to enlarge beyond their nominal size as inflation pressure rises. This has the advantage of allowing a slightly undersized balloon to be used to reduce the risk of dissection, while leaving scope for an increase in balloon size by high pressure inflations later in the procedure to reduce residual stenosis without having to exchange the dilatation catheter.

The pressure capability of the balloon depends upon its inherent strength and thickness. Polyethylene terephthalate is the strongest balloon polymer, permitting a balloon wall thickness of only 0.0002 inch compared with the $0.002-0.003$ inch required for other materials. Thus polyethylene terephthalate balloons are low profile but have the disadvantage of increased fragility making them susceptible to damage during handling. Polyolefin copolymer is second to polyethylene terephthalate in terms of polymer strength but because balloons made of this material have thicker walls they are able to sustain higher inflation pressures, approaching 12 atmospheres for the SciMed "Strong" catheter. This is useful for adjusting the balloon diameter for sizing purposes (see above) and also makes the polymer suitable for unyielding calcified stenoses when high pressure inflations may be necessary. The low burst strength of polyvinyl chloride and polyethylene balloons makes them less appropriate for lesions of this type.

The transverse diameter of the deflated balloon is an important determinant of whether a tight stenosis can be crossed, and manufacturers place great emphasis on it, advertising the lowest possible value often without any indication of how it was derived. As previously stated, polyethylene terephthalate balloons have potentially favourable profile characteristics $(0.031$ inch transverse diameter for the USCI Mini-Profile $2.0 \mathrm{~mm}$ balloon) although the balloon attachments may add 0.003 inch to the stated profile. These balloons, however, have no "memory" and may bunch while crossing tight stenoses. Polyvinyl chloride balloons have a different problem, tending to "wing" after an initial inflation and completely altering their profile characteristics. Balloons made of polyethylene and polyolefin copolymer have a better intrinsic memory and they retain their low profile wrap with repeated inflations. These polymers also have a lower coefficient of friction than polyvinyl chloride, and the Microglide coating now applied to the ACS polyethylene balloons has reduced friction still further, easing their passage through tortuous vessels and tight stenoses. Other manufacturers are applying similar lubricants to their balloon catheters.

\section{Catheter technology}

Over-the-wire systems are the most widely used with either eccentric or concentric lumens. The eccentric design provides a larger channel for the guide wire, facilitating distal injection of contrast and measurement of the transstenotic pressure gradient. Neither of these facilities is essential, however, and the more compact concentric design sacrifices both for a lower shaft profile and faster balloon inflation and deflation. The lower the shaft profile the better the visualisation provided by proximal injection of contrast through the guiding catheter (a feature of special importance in the current era of complex multivessel angioplasty). Over-the-wire dilatation catheters are now available with shaft diameters as small as $3.5 \mathrm{~F}$ (SciMed Skinny, USCI Miniprofile, Medtronic Thruflex) tapering to $3.0 \mathrm{~F}$ distally (SciMed Skinny). Catheter shafts are made of polyethylene in most cases, a flexible compound that provides maximum "trackability" for reaching stenoses throughout the coronary tree. Polyvinylchloride is also used (USCI, except Simplus and Mini-Profile). This is stiffer and provides more "pushability" for advancing the catheter across tight stenoses. Generally speaking, however, pushability is bought at the expense of trackability and catheters (for example Profile Plus, Trac Plus) are now available with a polyvinylchloride shaft and a flexible neck behind the balloon, which to some extent combine both features. Recently available is the low profile Medtronic Thruflex catheter which has a novel spring-coil, polyethylene coated, shaft with an extra flexible distal segment combining pushability and trackability.

The Schneider monorail catheter has a polyvinylchloride shaft and comes with both polyethylene terephthalate and polyvinylchloride balloons. The guide wire lumen is restricted to the distal $17 \mathrm{~cm}$ where the shaft diameter is $3.6 \mathrm{~F}$. The remainder of the shaft has a single inflation-deflation lumen and, consequently, a very low profile $(3.0 \mathrm{~F})$. The ACS RX catheter has a similar design with a slightly longer guide wire lumen $(25 \mathrm{~cm})$. Probably the major advantage of the monorail system is that it allows for the guide wire to be directed into the coronary artery before the catheter is introduced. This facilitates guide wire control during this critical stage of the procedure and ensures excellent visualisation from proximal injections of contrast. Once the guide wire is in place, the catheter can be run along it and positioned across the stenosis. So long as the guide wire is in position, access to the coronary artery is preserved and multiple catheter exchanges can be performed as necessary. Disadvantages of the monorail catheter include some loss of axial support which reduces pushability, though this problem has been partially resolved by lengthening the guide wire lumen from $9 \mathrm{~cm}$ to $17-25 \mathrm{~cm}$.

Fixed guide wire catheters have a single inflation-deflation lumen with a very low shaft profile. The most widely used has been the USCI Probe which has a Teflon coated $1.7 \mathrm{~F}$ steel shaft with a polyethylene neck and a polyethylene terephthalate balloon (transverse diameter of deflated balloon only $0 \cdot 20$ inch for a 
$2.0 \mathrm{~mm}$ balloon). The distal wire tip is 0.014 0.016 inch in diameter and either 1 or $2 \mathrm{~cm}$ long. The profile characteristics of the Probe and other fixed wire systems (for example SciMed ACE) ensure excellent visualisation and often enable high grade distal stenoses to be crossed. Moreover, these catheters can be used alongside conventional over-the-wire systems within the same $9 \mathrm{~F}$ giant lumen guiding catheter and are ideal for complex procedures requiring simultaneous dilatations of branch stenoses ("kissing balloon" technique, see below). The absence of a removable guide wire has important disadvantages, however; if a larger balloon size is required the catheter cannot be exchanged as safely as an over-thewire or monorail catheter, torque transmission is poor (which makes steering difficult), and it may be impossible to advance the balloon across the stenosis if the tip of the wire jams in the distal vessel wall.

\section{GUIDE WIRE}

Guide wires for percutaneous transluminal coronary angioplasty range in diameter from 0.010 to 0.018 inch and are usually Teflon coated to reduce friction within the catheter and coronary artery. ACS wires also come coated with Microglide to improve friction characteristics further. Full body wires in which the core extends to the tip have greatest torque control (steerability), are easy to shape, and provide maximal axial support, which is particularly useful for crossing totally occluded vessels. However, because these wires are stiff and liable to damage the intima, floppy guide wires in which the core stops $2-3 \mathrm{~cm}$ short of the tip are preferred for most cases. The 0.014 inch floppy wires from ACS and USCI are the most widely used and if properly shaped can be guided across stenoses throughout the coronary tree.

It is now generally accepted practice in percutaneous transluminal coronary angioplasty that guide wire access for catheter exchange should be continuously available until the procedure is safely completed. In the past this demanded removal of the standard guide wire and substitution of a $300 \mathrm{~cm}$ exchange guide wire for each catheter exchange. The procedure was cumbersome but now is rarely necessary with the introduction of extendable guide wires in which the extension is attached to the standard guide either by a screwing (USCI) or docking (ACS) mechanism. Use of the monorail technique, of course, avoids the problem altogether because the standard guide wire is used as a sliding rail for catheter exchange.

A more recent development in guide wire technology has been the SciMed dilating guide wire (DGW) with a $1.5 \mathrm{~mm}$ balloon and a $3 \mathrm{~cm}$ flexible tip that will pass through the lumen of the Trac or Trac Plus dilatation catheters. This allows predilatation of tight stenoses before the balloon catheter is advanced to complete the procedure. ${ }^{4}$ Though this technique is theoretically attractive, experience is limited and its value remains to be established.

\section{Procedural guidelines}

In planning an angioplasty procedure, the operator must select the guiding catheter, dilatation catheter, and guide wire most appropriate to the case in hand. The choice will be influenced largely by personal experience, and a limited range of familiar equipment will be satisfactory for most procedures.

The guiding catheter is critical to the success of the procedure and if it is not firmly seated in the coronary ostium and directed along the axis of the diseased artery the chances of traversing a tight stenosis or occlusion are considerably reduced. Most operators prefer the femoral approach with conventional Judkins catheters, particularly for procedures in the left anterior descending and right coronary arteries; an Amplatz catheter often provides better direction and support for circumflex lesions. Nevertheless, for shepherd's crook right coronary arteries or other anatomical variants alternative guide catheters may be necessary and in such cases the brachial approach is sometimes better. Side hole catheters are rarely necessary for angioplasty of the left coronary artery but many operators use them routinely for the right coronary artery where there is greater risk of catheter wedging and interrupting coronary perfusion. The guiding catheter is usually required to provide "passive" back up support and is positioned in the coronary ostium by conventional diagnostic techniques. In more difficult procedures, however, "active" backup support may be required, with deep, often superselective, engagement being used to provide axial stability. This demands considerable care and should only be attempted if the proximal coronary artery is free of disease and large enough to accept the guiding catheter. Guiding catheters designed for active placement are now available (Medtronic SL series) with a long $(9 \mathrm{~cm})$ flexible distal segment suitable for deep engagement.

For single vessel angioplasty of a proximal stenosis equally good results can be expected from an over-the-wire or monorail system with a floppy guide wire. Because the monorail technique gives better guide wire control and visualisation some operators prefer to use it for distally located tight stenoses, though fixed wire low profile catheters are also effective. ${ }^{56}$ If the stenosis lies close to an important side branch, this should first be protected by insertion of a guide wire (to provide access in the event of occlusion) before proceeding to angioplasty of the main vessel. ${ }^{7}$ If the stenosis affects the branch vessel, many operators insert a low profile fixed wire dilatation catheter across it and a second dilatation catheter in the main vessel, inflating both balloons simultaneously (the "kissing balloon" technique). ${ }^{89}$ Specially designed angled balloons are also available for stenoses at branch locations; experience with their use is limited. ${ }^{1011}$

Choice of balloon size is important. ${ }^{1213}$ Many operators intentionally "oversize" the balloon to achieve a widely patent vessel. This may increase the risk of dissection and it is more prudent to match the balloon size to the vessel, and perhaps to use a distensible (non-poly- 
ethylene terephthalate) balloon which leaves the option for hyperinflating the balloon towards the end of the procedure if adequate dilatation has not been achieved. There is no evidence that the duration of individual inflations influences the final result though the cumulative inflation time may be a more important variable..$^{14} 15$

Multivessel angioplasty is associated with a somewhat greater risk ${ }^{16}$ and it is usually the policy in our hospital to stage the procedure, dilating the most critical stenosis first and, if successful, proceeding to the other lesions during a later procedure. When more than one stenosis is dilated during a single procedure, guide wire access to each stenosis should if possible be retained until the procedure is complete.

In complete coronary occlusion the results of angioplasty are less satisfactory, with success rates of between 50 and $55 \% .{ }^{1718}$ There is evidence that the outcome is better in recently occluded vessels and in vessels with well preserved collateral flow beyond the occlusion. ${ }^{18}$ At the London Chest Hospital a stiff guide wire (ACS 0.014 inch $\mathrm{Hi}$-Torque intermediate) and a low profile, low friction catheter (ACS SULP with a $2.0 \mathrm{~mm}$ Microglide-coated balloon) are preferred. Maximum support for the guide wire is essential and this is usually achieved by active engagement of the guiding catheter while the dilatation catheter is advanced down the coronary artery to the occlusion. Alternative techniques are also receiving attention. The USCI 0.038 inch floppy tipped hollow guide wire and the Schneider 0.021 inch floppy tipped Magnum guide wire (with a $1 \mathrm{~mm}$ terminal olive) are support devices for a conventional guide wire and dilatation catheter respectively; both have been recommended for angioplasty of occluded vessels. ${ }^{1920}$ The Medtronic Omniflex catheter has also been recommended for this purpose. ${ }^{21}$ This is a low profile, spring-coil, polyethylene coated catheter with a $2.9 \mathrm{~F}$ shaft and a 0.034 inch transverse deflated diameter for a $2.0 \mathrm{~mm}$ balloon. A novel feature of the catheter is the "fixed wire" tip that can be rotated and flexed by a simple control system at the proximal end. The combination of pushability and tip control presumably accounts for its value in opening up occluded coronary arteries. Acute coronary occlusion complicating angioplasty is a medical emergency for which patients may need other interventions as preludes to bypass surgery. An autoperfusion catheter can be inserted over a guide wire placed across the occlusion..$^{22}$ Multiple perforations along the distal portion of the catheter allow blood to flow into the holes proximal to the occlusion and out through the holes distal to it. This protects against ischaemic damage in the same way that injections of arterial blood through the central lumen of a conventional balloon catheter have been shown to do. ${ }^{23}$ However, the autoperfusion catheter depends upon an adequate head of arterial pressure to function effectively and this is not always available when the catheter is needed.

I thank Carol Walker, clinical nurse manager of the catheterisation laboratory at the London Chest Hospital, for help in the preparation of this paper.

de Feyter PJ, Serruys PW, van den Brand M, Suryapranata $H$, Beatt $K$. Short term results of percutaneous transluminal coronary angioplasty with the monorail technique: experience in the first 1000 patients. Br Heart $J$ 1990;63:253-9.

2 Detre K, Holubkov R, Kelsey S, et al. Percutaneous transluminal coronary angioplasty in 1985-1986 and 1977-1981. The National Heart, Lung, and Blood Institute Registry. N Engl J Med 1988;318:265-70.

3 Werns SW, Topol EJ. Review of hardware for PTCA. $J$ Interven Cardiol 1988;1:3-14.

4 Rizzo TF, Ciccone J, Werres R. Dilating guidewire: use of a new ultra-low-profile percutaneous transluminal of a new ultra-low-profile percutaneous transluminal coronary angioplas

5 Thomas ES, Williams O, Neiderman AL, Douglas JS, King SB. Efficacy of a new angioplasty catheter for severely narrowed coronary lesions. J Am Coll Cardiol 1988; 2:694-702.

6 Dorrow G, Lewin RF, Mathiak L. Probe, a balloon wire: initial experience. Cathet Cardiovasc Diagn 1988;14: 286-8.

7 Bowser MA, Lozner EC, Johnson LW. Simplified two-wire technique for bifurcation lesions during coronary angioplasty. Cathet Cardiovasc Diagn 1989;16:136-8.

8 Myler RK, McConahay DR, Sterzer SH, et al. Coronary bifurcation stenoses: the kissing balloon Probe technique via a single guiding catheter. Cathet Cardiovasc Diagn 1989;16:267-78.

9 Thomas ES, Williams DO. Simultaneous double balloon coronary angioplasty through a single guiding catheter for bifurcation lesions. Cathet Cardiovasc Diagn 1988;15: $260-4$

10 Slack JD, Pinkerton CA. Complex coronary angioplasty: use of extended and angled balloon catheters. Cathet Cardiovasc Diagn 1987;13:284-7.

11 Vivekaphirat V, Zapala C, Fosch AE. Clinical experience with the use of the angled balloon dilatation catheter. Cathet Cardiovasc Diagn 1989;17:121-5.

12 Roubin GS, Douglas JS, King SB, et al. Influence of balloon size on initial success, acute complications and restenosis after percutaneous transluminal coronary angioplasty. Circulation 1988;78:557-65.

13 Nichols AB, Smith R, Berke AD, Shlofmitz RA, Powers ER. Importance of balloon size in coronary angioplasty. $\mathrm{J} \mathrm{Am}$ Coll Cardiol 1989;13:1094-100.

14 Faxon DP, Kelsy F, Ryan TJ, McCabe CH, Detre K. Determinants of successful percutaneous transluminal coronary angioplasty: report from the National Heart, Lung, and Blood Institute Registry. Am Heart J 1984;108:1019-23.

15 Timmis AD, Crick JCP, Griffin B, Sowton E. Factors predictive of early angiographic and functional success following percutaneous translumin
plasty. Eur Heart $J 1986 ; 7: 602-8$.

16 Deligonul U, Vandormael MG, Kern MJ, Zelman R, Galan $\mathrm{K}$, Chaitman BR. Percutaneous transluminal coronary angioplasty in two and three vessel coronary disease: information and speculation. $J \mathrm{Am}$ Coll Cardiol 1988;11:1180-2.

17 Holmes DR, Vlietstra RE, Reeder GS, et al. Angioplasty in otal coronary artery occlusion. J Am Coll Cardiol 1984;3:845-9.

18 Kereiakes DJ, Selmon MR, McAuley BJ, McAuley DB, Sheehan DJ, Simpson JB. Angioplasty in total coronary artery occlusion experience in 76 consecutive patients. $J$ Am Coll Cardiol 1985;6:526-33.

19 Smith LDR, Katritsis D, Webb-Peploe MM. Use of a hollow wire to facilitate angioplasty of occluded vessels. $\mathrm{Br}$ Heart J 1989;61:326-30.

20 Meier B, Carlier M, Finci L, et al. Magnum wire for balloon recanalisation of chronic total coronary occlusions. Am J Cardiol 1989;64:148-54.

21 Hamm CW, Schofer J, Kupper W. Improved recanalisation of coronary occlusions with a new catheter system. Circof coronary occlusions with a
ulation 1988;78(suppl II):82.

22 Hinohara T, Simpson JB, Phillips HR, Stack RS. Transluminal intracoronary reperfusion catheter: a device to maintain coronary perfusion between failed coronary angioplasty and emergency coronary bypass surgery. $\mathrm{J} \mathrm{Am}$ Coll Cardiol 1988;11:977-82.

23 Timmis AD, Griffin B, Crick JCP, Sowton E. Arterial blood infusion for myocardial protection during percutaneous transluminal coronary angioplasty. Eur Heart $J$ 1987;8: $340-6$. 